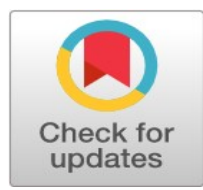

\title{
Exploring the relationship between leadership, organizational culture, trust, and effectiveness of knowledge sharing by forced learning
}

\author{
Lee Alfred Bo Shing ${ }^{1^{*}}$, Pu Jenny Xiaodie ${ }^{2}$ \\ 1,2 The Hong Kong Polytechnic University, Hung Hum, Hong Kong
}

\author{
Index Terms \\ leadership \\ Culture \\ Trust \\ Knowledge sharing \\ Forced learning
}

Received: 21 January 2017

Accepted: 11 March 2017

Published: 21 April 2017

\begin{abstract}
A focal firm is dependent on the suppliers and sometimes needs to develop the suppliers to improve their capabilities. Several development programs are available. Knowledge sharing in the supply chain is one of the supplier development programs. In the literature, it has shown that there is a relationship between knowledge sharing and leadership, organizational culture, and trust. However, the mechanism of knowledge sharing is scarcely studied. With this study, we aim to fill the knowledge gap by exploring the relationship between knowledge sharing by forced learning and leadership, collaborative culture, and trust. Analysis of empirical data by partial least square structural equation modeling (PLS-SEM) suggests that knowledge sharing by forced learning is justified if the supplier firm has appropriate leadership and collaborative culture, and trust exists between the business partners.
\end{abstract}

(C) 2017 The Author(s). Published by TAF Publishing.

\section{INTRODUCTION}

Nowadays, a focal firm retains the core competence within its organizational boundary and outsources other capabilities that are generally available in the market to the upstream suppliers to increase the firm's competitive edge (Huo, Qi, Wang \& Zhao, 2014; Sundar \& Al Harthi, 2015). This practice is common for equipment manufacturers in mainland China, for instance, the focal firm. However, the suppliers' capabilities are not always up to expectation and the focal firm implements supplier development program to elevate the suppliers' capabilities (Mortensen \& Arlbjorn, 2012). Among the supplier development programs (Li, Humphreys, Yeung \& Cheng, 2007; Mortensen \& Arlbjorn, 2012; Routroy \& Pradhan, 2013) knowledge sharing is an advanced activity, but it is resource-intensive and thus the least attractive (Kotabe, Martin \& Domoto, 2003; SánchezRodríguez, Hemsworth \& Martínez-Lorente, 2005). How- ever, several studies report that knowledge sharing is not always successful (Giannakis, 2008; Mohanty, Gahan \& Choudhury, 2014; Sako, 2004).

The focal firm and the suppliers should cultivate the collaborative culture and trustworthy relationship to facilitate the supplier development program to enhance the supplier's performance (Blonska, Storey, Rozemeijer \& De Ruyter, 2013). The leadership role taken by an organization leader has an impact on cultivating the collaborative culture at each level to allow for effective knowledge sharing among the organization's members (Yang, 2007) and across organizational boundaries (Islam, Ahmed, Hasan \& Ahmed, 2011).

Per resource-based view, knowledge is the critical asset for organizations (Cai, Goh, De Souza \& Li, 2013). Therefore, inter-organizational knowledge sharing involves risk taking and the issues of trust and power among the sup-

\footnotetext{
${ }^{*}$ Corresponding author: Lee Alfred Bo Shing

†Email: abslee1@netvigator.com
} 
ply chain players (Cai et al., 2013). When commitment and trust are in place, knowledge sharing becomes more effective (Cai et al., 2013). Trust is suggested to be the cornerstone for both inter-firm and interpersonal knowledge sharing (Chen, Lin \& Yen, 2014; Teh \& Sun, 2011). Leadership, collaborative culture, and trust are the vital elements affecting knowledge sharing (Islam et al., 2011). There is a lot of discussion of knowledge sharing in the extant literature (Cai et al., 2013; Chen et al., 2014; Islam et al., 2011; Giannakis, 2008; Kotabe et al., 2003; Mohanty et al., 2014; Sánchez-Rodríguez et al., 2005; Sako, 2004; Teh \& Sun, 2011; Yang, 2007).

However, literature has scarce discussion of the factors, namely, leadership, collaborative culture, and trust on the effectiveness of knowledge sharing by forced learning (KSFL). Teaching, as described by Kline (2015), is a forced learning method, such that the knowledge sender communicates the knowledge to the receiver who receives the knowledge passively.

The effectiveness of KSFL is therefore worth in-depth investigation. We aim to fill this knowledge gap by empirical study to explore the complex relationships that leadership, collaborative culture, and trust have with KSFL. Besides, we also aim to get an insight on what to focus - whether it is leadership, organizational culture, or trust, the most influential factor(s) for company to obtain the most effective KSFL to justify the investment of KS in supplier development.

\section{LITERATURE REVIEW AND HYPOTHESIS DEVELOP- MENT \\ Knowledge}

Davenport \& Prusak (as quoted in He, Gallear \& Ghobadian, 2011; as quoted in Islam et al., 2011) define knowledge as a collection of experience, values and information that have a reference and influential explanation about the new experience and information that are being documented or stored, and the programs, process, rules, and norms. Knowledge is considered as one of the intangible market-based assets (Asare, Brashear \& Kang, 2013; Cai et al., 2013). Knowledge is classified into two dimensions, namely explicit and implicit (Wu \& Lin, 2013). Explicit knowledge is documented, codified, stored and easily available from the public (Giannakis, 2008; Wu \& Lin, 2013; Nagati \& Rebolledo, 2013).

Implicit knowledge is intangible and individualized, i.e., attached to an individual and it can only be acquired by others by pronunciation, demonstration, and hands-on teaching by personal contacts (Giannakis, 2008; Nagati \& Re- bolledo, 2013; Nir, Ding \& Chou, 2012; Wu \& Lin. 2013).

\section{Knowledge Sharing in Supply Chain}

Supply chain partners share knowledge to help boost collaborative relationship to increase market competitiveness (Cai et al., 2013). Interaction between supply chain partners during knowledge transfer sparks new idea and knowledge (Cai et al., 2013).

The literature asserts that knowledge is an asset in the resource-based view, knowledge sharing involves risk taking and issues of trust and power among supply chain players (Albino, Garavelli \& Schiuma, 1998; Blonska et al., 2013; Cai et al., 2013; Li et al., 2007; Mohanty et al., 2014; Nagati \& Rebolledo, 2013; Routroy \& Pradhan, 2013; Wagner, 2011; Wu, Chuang \& Hsu, 2014). Liu, Chen \& Niu (2015) suggest four factors affecting knowledge sharing in the supply chain. The first factor is organizational culture. The culture of every firm is different (Liu et al., 2015). Although integrating different culture can enhance supply chain collaboration, Liu et al. (2015) stress that integration of culture across collaborating firms is difficult.

The second factor is the sharing of benefits arising from collaboration without the suspicion that supply chain partner may take opportunistic advantages (Liu et al., 2015). Sharing the benefits arising from knowledge sharing differently is the third factor (Liu et al., 2015). Cadden, Marshall \& Cao (2013) point out that firms with outward-looking collaborative culture and trust in the supply chain partners will have better supply chain performance. Cai et al. (2013) suggest a collaborative environment enhancing knowledge sharing and eventually the supply chain performance. Cai et al. (2013), Nagati \& Rebolledo (2013) and others argue that trust, among other factors, is essential for more effective and efficient knowledge sharing. Although extensive research has investigated the sharing of knowledge in supply chain networks, studies examining the specific mechanism in knowledge sharing remain sparse. Therefore, it would be a significant contribution to shed some light on knowledge sharing by the forced learning, which may help the focal firms to choose a more effective supplier development program.

\section{Knowledge Sharing by Forced Learning}

Halmos (1994) explains knowledge as being "what to remember", "how to use" and "why it is" and the teaching of knowledge is "what" adjoins with "how" and then adjoins with "why". Kline (2015) elaborates several theories of teaching. The culture-based theories describe teaching ac- 
cording to its apparent characteristics that include (a)

the knowledge sender determines to send out knowledge, (b) knowledge is channeled in one way from the sender to the receiver, (c) the receiver receives the sent knowledge passively, (d) the knowledge is communicated verbally, (e) the activity is accepted as "teaching" by both the knowledge sender and the receiver (Kline, 2015). Accordingly, Kline (2015) describes teaching as a passive way of receiving knowledge and concludes that teaching is a type of forced learning.

Therefore, knowledge sharing by forced learning (KSFL) - teaching - is a passive way of sharing knowledge. One of the obvious choices for the focal firm to share knowledge with suppliers is formal classroom teaching, where the employees of a supplier attend teaching sessions and receive the shared knowledge passively. Forced learning occurs during the teaching sessions.

\section{Leadership}

Leadership is positively associated with knowledge sharing (Islam et al., 2011; Yang, 2007). Leadership refers to what guides organizational members to focus their energy to achieve common goals (Islam et al., 2011; Schein, 1984). The leader demonstrates how to make knowledge sharing happen and provides needed encouragement (Islam et al., 2011).

The leader coordinates the knowledgeable employees within the firm to share knowledge in collaborative activities (Islam et al., 2011). Thereby, the leader has an important role in knowledge sharing and in the generation of new knowledge (Islam et al., 2011). Therefore, as argued by Islam et al. (2011), leadership is important in creating a positive cultural environment for knowledge sharing within and across the firm's boundaries, and thus is critical in knowledge creation for the sustainability of the organization. Based on the above discussion of knowledge sharing and leadership, we hypothesize the following relationship: H1: Leadership has a positive direct effect on the effectiveness of KSFL.

\section{Collaborative Culture}

Schein (1984) defines organization culture as a set of fundamental beliefs that are created and shared by the members of the organization. Organizational culture guides the individuals' behaviour in solving problems, and is deeply rooted within the boundaries of the organization such that the organizational members including new members will follow. Hartnell, Ou \& Kinicki (2011) believe that organizational culture is collective values, beliefs and un-manifested practices and has an impact on organizational effectiveness. Miroshnik \& Basu (2014) argue that organizational culture is the residual of learning process with the evidences of patterns of practices, efficient and effective integration process, knowledge sharing within the organizational boundaries and whether process is repetitive and how assets are transformed.

Cao, Huo, Li \& Zhao (2015), firm has to nurture an appropriate organizational culture to cultivate trustworthy behaviour and skills in inter-organizational relationship. Schein (1984) concludes that organizational culture begins with the values, beliefs and the assumption held by the leader of an organization (as quoted in (Gál, 2012)). As an organization develops, the values, beliefs and assumption will drive new concepts of values, beliefs, and assumption by the new leadership (Gál, 2012). Gál (2012) argues that in this way leadership impacts on organizational culture. Per Gál (2012), there are four dimensions of organizational culture which are forward looking, cooperation, decentralization and sharing of rewards respectively. Organizational culture will affect firm in sharing knowledge with its supply chain partners (Cao et al., 2015; Liu et al., 2015). Cadden et al. (2013) argue that the collaborative culture, which is an outward looking culture, is the appropriate type of culture for knowledge sharing in the supply chain. Our discussion of collaborative culture and KSFL leads to the following hypotheses:

H2: Leadership has a positive direct effect on collaborative culture.

H3: Collaborative culture has a positive direct effect on the effectiveness of KSFL.

\section{Trust}

Per Starnes, Truhon \& McCarthy (2010), trust is an intangible attribute of a human being. Trust refers to a collection of beliefs that, during the interaction between a trustor and a trustee, is held by the trustor that the actions of the trustee will have positive outcomes on the trustor (Islam et al., 2011; Starnes et al., 2010). As aforementioned, leadership has an impact on the development of trust within the organizational culture (Cao et al., 2015; Gál, 2012; Schein, 1984).

Organizational trust is an organizational behaviour borrowing similar concept to explain the intangible behaviour found in human beings (Starnes et al., 2010). Starnes et al. (2010) explain that there are three variations of or- 
ganizational trust which are inter-organizational trust, intra-organizational trust, and inter-personal trust. While inter-organizational trust is the trust between two organizations, intra-organizational trust refers to the trust between an employee and the organizational leaders and inter-personal trust is related to the relationships between workers within a work group.

Volken (2002) argues that trust functions as a cultural resource, making interaction between parties more cost efficient by requiring less control and improving information exchange. Trust takes shape from an extended period of interaction with observable evidence (Volken, 2002). Fawcett, Jones \& Fawcett (2012) argue that trust is an ultimate resource in and the foundation for the collaboration between supply chain partners such as $\mathrm{P} \& \mathrm{G}$, Honda, and Wal-Matt in their case study. Trust is dependent on the commitment capability and performance capability (Fawcett et al., 2012).

When both the commitment and performance capabilities are at high level, trust between the parties will become mature and the intensity to exchange information and knowledge will improve (Fawcett et al., 2012). Per above discussion, we posit the following hypotheses:

H4: Collaborative culture has a positive direct effect on trust.

H5: Leadership has a positive direct effect on trust.

H6: Trust has a positive direct effect on the effectiveness of KSFL.

Leadership is the ultimate construct developing organizational culture, including collaborative culture and trust (Schein, 1984). When the construct collaborative culture is sufficiently nurtured to influence organizational behaviour, we posit the following:

H7: Leadership has an indirect effect on the effectiveness of KSFL via the mediation variable collaborative culture.

H8: Leadership has an indirect effect on trust via the mediation variable collaborative culture.

H9: Leadership has an indirect effect on the effectiveness of KSFL via the mediation variable trust.

H10: Collaborative culture has an indirect effect on the effectiveness of KSFL via the mediation variable trust.

H11: Construct collaborative culture and trust jointly mediate the relationship between leadership and KSFL.

\section{RESEARCH METHODOLOGY}

\section{Research Design}

The present research is a study with the author's participation, but without observation design (Garson, 2013:12).
One of the authors has a collaborative customer-supplier relationship with the participating suppliers (PSUPs) such that the PSUPs were willing to participate in this research. The participating subjects (PSUBs) were selected by each PSUP.

The PSUBs may or may not have any prior knowledge sharing treatment similar to teaching. The control variables are the treatment content and the knowledge sharer (KSR), and by keeping the controlled variables constant, the response from each PSUB is collected on the common ground. The PSUBs attended eight-hour teaching session and then completed the survey questionnaires to provide data for analysis.

The KSR is one of the authors having a customersupplier relationship with the PSUPs and was responsible for conducting teaching. The classroom teaching was to share explicit and implicit knowledge in lean management, based on the writings by Liker (2004), Nicholas (1998) and Shingo (1988). The KSR asked the PSUBs if they have any questions after every topic during the teaching session. Each PSUB was assigned a unique number and was offered an incentive of RMB20.00 for completing the questionnaire.

After the questionnaires were collected, they were reviewed for completeness. Questionnaires with missing data were returned to the corresponding PSUBs to provide the missing data. Therefore, the response rate of the survey questionnaire is $100 \%$. The PSUPs have a suppliercustomer relationship with one of the authors. Some of the prerequisites of the PSUPs are:

(a) The supplier is willing to participate.

(b) The supplier has an organizational structure in place.

(c) The supplier had sufficient employees to offer three teams of PSUBs.

Bearing with these prerequisites, the author screened through the suppliers' base and eventually only eight PSUPs were available. The other suppliers did not meet the prerequisites. However, the PSUPs are representative in their industry. The PSUPs select their potential employee to attend the knowledge sharing session. The PSUBs include the front line workers to senior executives. The KSR explained the meaning of the special terms in the survey questionnaire before the questionnaire is distributed to the PSUBs. The information of the participating firms and the demographic information of the participating subjects are shown in Table 1 and Table 2 respectively.

\section{Measuring Instruments}

There are four constructs, namely leadership, collaborative 
culture, trust and KSFL in the model. The measurement instruments developed to measure the four constructs are validated in literature and are adapted from existing instruments (Cai et al., 2013; Yang, 2007). The original measurement items are prepared in English and are translated into Chinese. Two non-professionals reviewed the translation to ensure that there was no misunderstanding of intent. Before the questionnaire was distributed to the PSUBs, the special terms used in the questionnaire were explained at the end of the teaching session to reduce possible measurement errors.

We used the Likert 7 scale to measure each measurement item, with 1 representing strongly disagree and 7 representing strongly agree. The use of the Likert 7 scale is to increase the sensitivity of the scale and extraction of variance (Yang, 2007). We used multiple-item measurement instruments to measure the constructs as recommended by Diamantopoulos, Sarstedt, Wilczynski \& Kaiser (2012). The measurement items were randomized in the survey questionnaire to prevent the subject from acquiescence bias (Anastas, 1999:388; Buckingham \& Saunders, 2004:80; Garson, 2013). There are altogether 77 items to measure the constructs and 5 items to collect demographic information. The measurement items of the constructs leadership, trust and KSFL are reflective whereas the measurement items for the construct collaborative culture are formative (Hair, Hult, Ringle \& Sarstedt, 2014).

\section{Sample Size}

Hair et al. (2017:25) point out that the sample size should be determined by its statistical power with regard to the background of the model and data characteristics. The sample size shall be sufficiently large to provide the statistical significance (Faul, Erdfelder, Lang \& Buchner, 2007). We used the statistical software $\mathrm{G}^{*}$ Power 3 to conduct a priori power analysis (Faul et al., 2007). We assumed an effect size of $0.3, \alpha=0.05,1-\beta$ (power level) $=0.95$. Other parameters were chosen as per software default. The minimum sample size is suggested to be 134 , while the actual sample size of this study is 199 , implying that our sample has sufficient statistical significance.

\section{Data Analysis}

Covariance-based structural equation modeling (CB-SEM) is a confirmatory analysis (Jöreskog, 1978, 1982) while the PLS-SEM is more suitable for exploratory analysis (Hair et al., 2017).

The goal of this study is to identify the effects of leadership, organizational culture, and trust on the effectiveness of KSFL. Because of the exploratory nature of this study and the small sample size encountered, it is adequate to use the PLS-SEM (Hair et al., 2017). Therefore, we chose the PLS-SEM, using the software SmartPLS 3.0 to analyze the empirical data (Ringle, Wende \& Becker, 2015). The manifest variables of leadership, trust and KSFL are reflective whereas the manifest variables of organizational culture are formative (Hair et al., 2017; Wong, 2013). The attributes of the original manifest variables, i.e., reflective, or formative, adapted from Yang (2007) and Cai et al., (2013) are retained in this study.

TABLE 1. Information of participating firms

\begin{tabular}{lllccc}
\hline \hline Participating Firms & Industry & Background & No of Participating Subjects & No of Employees & Percentage of Participation \\
\hline PSUP-1 & Electric motor & Private, ex. SOE & 22 & 1300 & $1.70 \%$ \\
PSUP-2 & Electric motor & Joint venture & 11 & 63 & $17.46 \%$ \\
PSUP-3 & Electric motor & Private & 23 & 410 & $5.85 \%$ \\
PSUP-4 & Electric drive & Foreign investment & 30 & 223 & $13.45 \%$ \\
PSUP-5 & Pipe fitting & Private & 23 & 250 & $9.20 \%$ \\
PSUP-6 & Valve Private & 30 & 360 & $8.33 \%$ & 260 \\
PSUP-7 & Electric drive & Private & 21 & 538 & $7.08 \%$ \\
PSUP-8 & Electric motor & Private & 39 & & \\
\hline \hline
\end{tabular}

\section{EMPIRICAL RESULTS}

\section{Evaluation of Measurement Model}

Per Hair et al. (2017), the evaluation of empirical data is to test how well the data fit the theory by a systematic review procedure. We follow the guidelines to report the assessment of the PLS-SEM model (Hair et al., 2017; Wong, 2013). The measurement model consists of reflective and forma- tive measurement items. Constructs measured by reflective items are tested for their outer loadings (OL), composite reliabilities (CR) and the average values extracted (AVE) with results shown in Table 3, while measurement models with formative measurement variables are tested for their convergent validity (CV), collinearity (COL) and, significance and relevance with results in Table 4, Table 5 and Figure 1. 
11 out of 31 reflective measurement items had OL smaller than 0.7. 9 of the 11 reflective measures of which the OLs were less than 0.7 were removed while the reflective measure PRT-12 that had OL lower than 0.7 was retained in the model because the composite reliability achieved was justified to retain the measure in the model (Hair et al., 2017:113). Therefore, the reflective indicators in the reflective measurement model had reached a satisfactory reliability level. The CR of the three reflective constructs was achieved at 0.838 and above, substantiating the internal consistency reliability. All AVEs achieved are higher than the threshold value of 0.5 , substantiating the convergent reliability (Table 3). Per Hair et al. (2017), discriminant validity is used to identify how much a construct is distinct from other constructs. However, the traditional crossloading evaluation and the Fornell-Larcker criterion could not detect discriminant validity issues satisfactorily (Hair et al., 2017:117). Therefore, per Henseler et al. (2015) recommendation, the heterotrait-monotrait ratio (HTMT) was used to evaluate the discriminant validity of reflective measures (as quoted in Hair et al., 2017). The HTMT ratios ob- tained were below 0.9, as shown in Table 6 indicating the reflective measures are distinct from each other (Hair et al., 2017). The assessment of the reflective measurement models substantiates that the reflective constructs are valid and reliable. We next assessed the measurement model of collaborative culture.

TABLE 2 . Demographic information of participating subjects

\begin{tabular}{llll}
\hline \hline Measures & Categories & Counts & Percentage \\
\hline Profession & Mechanical & 60 & $43.17 \%$ \\
& Electro-mechanical & 41 & $29.50 \%$ \\
& Electronic & 0 & $0.00 \%$ \\
& Hardware & 10 & $7.19 \%$ \\
& Valves & 28 & $20.14 \%$ \\
Position & Manager \& senior & 18 & $12.95 \%$ \\
& Supervisor & 29 & $20.86 \%$ \\
& Team leader & 14 & $10.07 \%$ \\
Age Under & Foreman & 14 & $10.07 \%$ \\
& Others & 64 & $46.04 \%$ \\
Education level Postgraduate \& above & 35 yr. & 71 & $51.08 \%$ \\
& $35-45$ & 39 & $28.06 \%$ \\
& Above 45 & 29 & $20.86 \%$ \\
Similar training & College & $25.18 \%$ & \\
& High school & 47 & $33.81 \%$ \\
& Others & 34 & $38.85 \%$ \\
& Yes & 90 & $64.75 \%$ \\
& No & 49 & $35.25 \%$ \\
\hline \hline
\end{tabular}

TABLE 3 . Convergent validity test, reflective measurement models

\begin{tabular}{|c|c|c|c|c|}
\hline Construct & Indicators & Factor Loadings & Composite Reliability & Average Variance Extracted \\
\hline \multirow{10}{*}{ Leadership } & LR-02 & $0.743^{* * *}$ & \multirow{10}{*}{0.927} & \multirow{10}{*}{0.559} \\
\hline & LR-04 & $0.724^{* * *}$ & & \\
\hline & LR-05 & $0.701^{* * *}$ & & \\
\hline & LR-06 & $0.772^{* * *}$ & & \\
\hline & LR-07 & $0.784^{* * *}$ & & \\
\hline & LR-10 & $0.759^{* * *}$ & & \\
\hline & LR-12 & $0.807^{* * *}$ & & \\
\hline & LR-13 & $0.713^{* * *}$ & & \\
\hline & LR-15 & $0.702^{* * *}$ & & \\
\hline & LR-16 & $0.762^{* * *}$ & & \\
\hline \multirow{7}{*}{ Effectiveness of KSFL } & PRT-01 & $0.763^{* * *}$ & \multirow{7}{*}{0.886} & \multirow{7}{*}{0.527} \\
\hline & PRT-02 & $0.718^{* * *}$ & & \\
\hline & PRT-03 & $0.731^{* * *}$ & & \\
\hline & PRT-05 & $0.71^{* * *}$ & & \\
\hline & PRT-07 & $0.725^{* * *}$ & & \\
\hline & PRT-08 & $0.767^{* * *}$ & & \\
\hline & PRT-12 & $0.659^{* * *}$ & & \\
\hline \multirow{3}{*}{ Trust } & TR-02 & $0.85^{* * *}$ & \multirow{3}{*}{0.838} & \multirow{3}{*}{0.635} \\
\hline & TR-03 & $0.822^{* * *}$ & & \\
\hline & TR-04 & $0.711^{* * *}$ & & \\
\hline
\end{tabular}

The collaborative culture is measured as formative variable. Per Edwards (2011), formative measures are specified as causes of constructs that become the composite concepts represented by combining their linear weights together. To evaluate a measurement model with formative measures, we followed the recommendations by Hair et al. (2017) to test the model's convergent validity, collinearity, and signi- ficance and relevance. There are 15 measurement items for the collaborative culture, among them 8 are formative and 7 are reflective. Reflective measures are included in the questionnaire to test the convergent validity of the formative measures (Hair et al., 2017). Convergent validity indicates the extent to which the measurement items correlate with each other (Hair et al., 2017). The magnitude 
of the path coefficients of the formative variables and the coefficient of determinant $\mathrm{R} 2$ of the reflective variables are $0.762(p$-value $=0)$ and $0.581(p$-value $=0)$ respectively, which are larger than the threshold values 0.7 and 0.5 (Table 5). The convergent validity of the formative measures is substantiated.

The next step is to test the collinearity by estimating the variance inflation factors (VIF). The VIF values of the formative measures range from 1.453 to 1.695 , which are less than 5 , which suggests that there is no collinearity issue (Table 6). The last step is to evaluate the significance of each formative measure by its outer weight. The outer weights of the formative measures range from 0.238 to 0.335 and are at a significant level of $p<0.01$ (Table 6) (Hair et al., 2017). Since the outer weights of the formative measures are relevant and significant, the measures are all retained in the formative measurement model (Hair et al., 2017).

TABLE 4 . Discriminant validity by Heterotrait-Monotrait Analysis, reflective measurement model

\begin{tabular}{llc}
\hline \hline ConstructsEffectiveness of KSFL & Leadership & Trust \\
\hline Effectiveness KSFL & & \\
Leadership & 0.814 & \\
Trust & 0.881 & 0.765 \\
\hline \hline
\end{tabular}

TABLE 5 . Redundancy test convergent validity formative measurement model

\begin{tabular}{ll}
\hline \hline & Path Coefficient Magnitude \\
\hline OC_formative $\rightarrow$ OC_reflective & $0.726^{* * *}$ \\
& $\mathrm{R} 2$ \\
OC_reflective & $0.581^{* * *}$ \\
\hline${ }^{*} p<0.1,{ }^{* *} p<0.05,{ }^{* * *} p<0.01$ &
\end{tabular}

TABLE 6 . Collinearity, significance, and relevance test of formative measurement model measurement model

\begin{tabular}{llll}
\hline \hline Measures (formative)VIF & Outer Weights & Outer Loading & \\
\hline OC-02 & 1.503 & $0.335^{* * *}$ & $0.776^{* * *}$ \\
OC-03 & 1.548 & $0.244^{* * *}$ & $0.735^{* * *}$ \\
OC-04 & 1.76 & $0.257^{* * *}$ & $0.777^{* * *}$ \\
OC-07 & 1.453 & $0.238^{* * *}$ & $0.707^{* * *}$ \\
OC-10 & 1.695 & $0.253^{* * *}$ & $0.763^{* * *}$ \\
\hline${ }^{*} p<0.1,{ }^{* *} p<0.05,{ }^{* * *} p<0.01$ & &
\end{tabular}

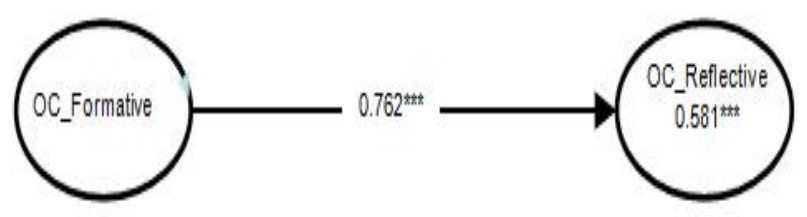

FIGURE 1. Redundancy analysis assessment of formative measurement model, organizational culture

ISSN: 2414-309X

DOI: $10.20474 /$ jabs-3.2.4

\section{Evaluation of Structural Model}

We followed the recommendations by Hair et al. (2017:190) in assessing the structural model. The first step is to assess the collinearity of the model. The collinearity assessment of the structural model is similar to the formative measures by estimating the VIF values. The VIF values estimates range from 1 to 3.905 (Table 7). The estimates are less than the threshold value of 5 , substantiating the constructs.

In the second step, we assessed the significance of the path coefficients. All path coefficients estimated are significant at $p<0.01$ level (Table 8) except for the path leadership $\rightarrow$ KSFL which is significant at $p<0.1$ level. The path coefficients estimated significant at $p<0.01$ level range from 0.298 to 0.396 . The coefficient of determination R2 of the constructs estimated is significant at $p<0.01$ level with the construct trust at 0.437 , KSFL at 0.693 and collaborative culture at 0.725 . We thus concluded that the predictive power of both the constructs collaborative culture and KSFL is better than moderate, and the construct trust is better than weak.

The third step in assessing the structural model is to estimate the impact of omitted construct on the endogenous constructs by estimating the effect sizes $\mathrm{f} 2$. The effect sizes $\mathrm{f} 2$ of the structural model span from no effect to larger effects, with f2 ranging from 0.004 to 3.119 (Table 9). In the fourth step, we assessed the Q2 of the structural model. The predictive relevance of the model is indicated by the Q2 values, which are obtained by blindfolding technique (Hair et al., 2017). No Q2 value estimated is below zero and the minimum estimated is 0.235 (Table 10), substantiating that the model has predictive relevance (Hair et al., 2017).

Lastly, we estimated the effect sizes q2, which are indicators of relative impact of the predictive relevance of the constructs. The estimated effect sizes q2 range from -0.006 to 0.061 , indicating that the effects are small to larger than small (Table 11). We assessed also the relationships of three structural models, namely, the leadership and KSFL (model 2) (Figure 3), the leadership and KSFL with mediator trust (model 3) (Figure 4) and the leadership and KSFL with mediator collaborative culture (model 4) (Figure 5) to get more insight into the mediating effect of the constructs. Table 12 shows the path coefficient and R2 for model 2. Both path coefficient and R2 of model 2 are significant at $p<0.01$ level.

The effect of R2 is moderate. For model 3, the path coefficients and R2 are shown in Table 13. Both path coefficients and R2 for model 3 are significant at $p<0.01$ level and the effects are weak to moderate. Table 14 shows the path coef- 
ficients and R2 for model 4, which are significant at $p<0.01$ level. The effect of $\mathrm{R} 2$ is at moderate level.

TABLE 7 . Path coefficient \& coefficient of determination of structural model (model 1)

\begin{tabular}{|c|c|c|c|}
\hline \multicolumn{2}{|l|}{ Path } & \multicolumn{2}{|c|}{ Path Coefficient } \\
\hline \multirow{2}{*}{\multicolumn{2}{|c|}{$\begin{array}{l}\text { Organizational culture } \rightarrow \text { Effectiveness KSFL } \\
\text { Organizational culture } \rightarrow \text { Trust }\end{array}$}} & $0.396^{* * *}$ & \\
\hline & & $0.298^{* *}$ & \\
\hline \multicolumn{2}{|c|}{ Leadership $\rightarrow$ Effectiveness KSFL } & $0.146^{*}$ & \\
\hline \multicolumn{2}{|c|}{ Leadership $\rightarrow$ Organizational culture } & $0.852^{* * *}$ & \\
\hline \multicolumn{2}{|c|}{ Leadership $\rightarrow$ Trust } & $0.388^{* * *}$ & \\
\hline \multicolumn{2}{|c|}{ Trust $\rightarrow$ Effectiveness of sharing } & $0.389^{* * *}$ & \\
\hline \multicolumn{2}{|c|}{ R2 Effectiveness KSFL } & $0.693^{* * *}$ & \\
\hline \multicolumn{2}{|c|}{ Collaborative culture } & $0.725^{* * *}$ & \\
\hline \multicolumn{2}{|c|}{ Trust } & $0.437^{* * *}$ & \\
\hline \multicolumn{4}{|c|}{$\begin{array}{l}\text { TABLE 8. Collinearity assessment (VIF) of structural } \\
\text { model (model 1) measurement model }\end{array}$} \\
\hline & Effectiveness KSFLCollaborative Cultu & Ire Leadership & Trust \\
\hline \multicolumn{4}{|l|}{ Effectiveness KSFL } \\
\hline \multicolumn{4}{|c|}{ Collaborative culture 3.795} \\
\hline Leadership & 3.905 & 1 & 3.637 \\
\hline Trust & 1.776 & & \\
\hline
\end{tabular}

TABLE 9. Effect Size $\mathrm{f}^{2}$ of structural model (model 1) model (model 1)

\begin{tabular}{ll}
\hline \hline Path & $\mathbf{f}^{2}$ \\
\hline Organizational culture $\rightarrow$ Effectiveness of KSFL & $0.17^{* *}$ \\
Organizational culture $\rightarrow$ Trust & 0.035 \\
Leadership $\rightarrow$ Effectiveness of KSFL & 0.004 \\
Leadership $\rightarrow$ Collaborative culture & $3.119^{* * *}$ \\
Leadership $\rightarrow$ Trust & 0.066 \\
Trust $\rightarrow$ Effectiveness of KSFL & $0.289^{* * *}$ \\
\hline${ }^{*} p<0.1,{ }^{* *} p<0.05,{ }^{* * *} p<0.01$ &
\end{tabular}

TABLE 10. Predictive relevance $Q^{2}$ of structural model (model 1)

\begin{tabular}{lllll}
\hline \hline & Excluding Leadership & Excluding Collaborative Culture & Full Model & \\
\hline Effectiveness of KSFL & 0.361 & 0.332 & 0.318 & 0.357 \\
Collaborative culture & & 0.436 & 0.437 & \\
Leadership & & & & \\
Trust & 0.235 & 0.256 & & 0.262 \\
\hline \hline
\end{tabular}

TABLE 11. $Q^{2}$ effect size of structural model (model 1 )

\begin{tabular}{ll}
\hline \hline Path & $\mathbf{q}^{2}$ \\
\hline Collaborative culture $\rightarrow$ Effectiveness of KSFL & 0.039 \\
Collaborative culture $\rightarrow$ Trust & 0.008 \\
Leadership $\rightarrow$ Effectiveness of KSFL & -0.006 \\
Leadership $\rightarrow$ Trust & 0.037 \\
Trust $\rightarrow$ Effectiveness of KSFL & 0.061 \\
\hline \hline
\end{tabular}

TABLE 12 . Path coefficient \& coefficient of determination $\mathrm{R}^{2}$ of model 2

\begin{tabular}{ll}
\hline \hline Path & Path Coefficient \\
\hline Leadership $\rightarrow$ Effectiveness KSFL & $0.735^{* * *}$ \\
& $\mathrm{R} 2$ \\
Effectiveness KSFL & $0.54 * * *$ \\
\hline${ }^{*} p<0.1,{ }^{* *} p<0.05,{ }^{* * *} p<0.01$ &
\end{tabular}

ISSN: $2414-309 X$

DOI: $10.20474 /$ jabs-3.2.4

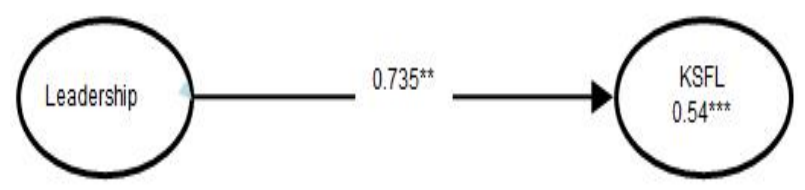

FIGURE 2 . Structural model without mediator effect (Model 2)

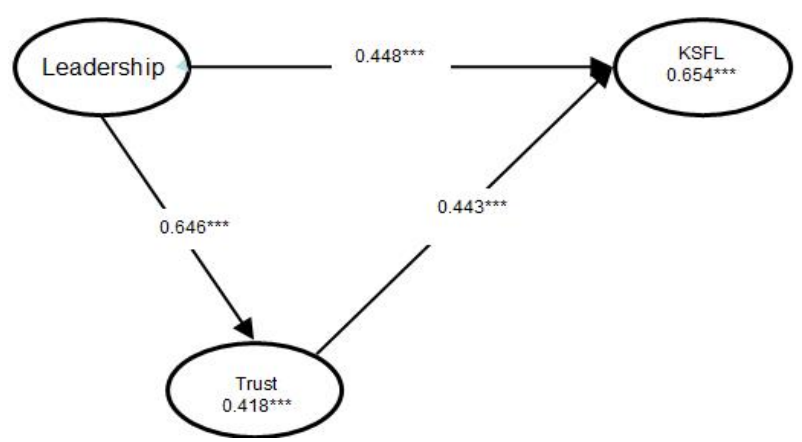

FIGURE 3 . Structural model with mediator trust effect (model 3)

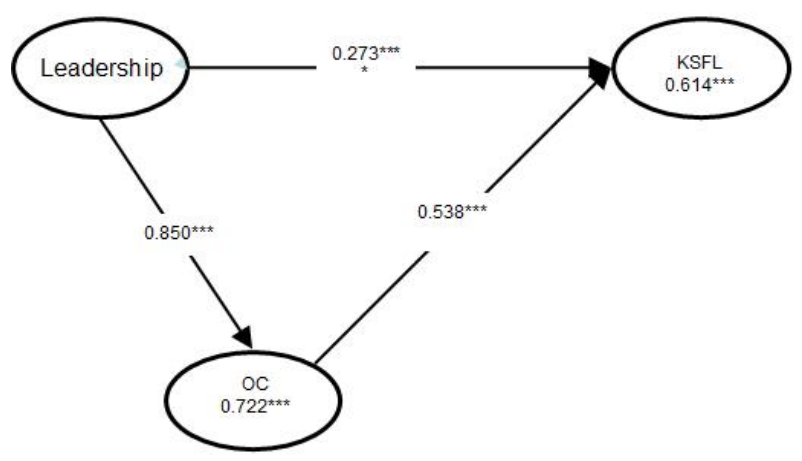

FIGURE 4. Structural model with mediator collaborative culture effect (model 4)

TABLE 13 . Path coefficient \& coefficient of determination of model 3

\begin{tabular}{ll}
\hline \hline Path & Path Coefficient \\
\hline Leadership $\rightarrow$ Effectiveness KSFL & $0.448^{* * *}$ \\
Leadership $\rightarrow$ Trust & $0.646^{* * *}$ \\
Trust $\rightarrow$ Effectiveness of sharing & $0.443^{* * *}$ \\
& $\mathrm{R} 2$ \\
Effectiveness KSFL & $0.654^{* * *}$ \\
Trust & $0.418^{* * *}$ \\
\hline${ }^{*} p<0.1,{ }^{* *} p<0.05,{ }^{* * *} p<0.01$ & \\
&
\end{tabular}


TABLE 14. Path coefficient \& coefficient of determination of model 4

\begin{tabular}{ll}
\hline \hline Path & Path Coefficient \\
\hline Collaborative culture $\rightarrow$ Effectiveness KSFL & $0.538^{* * *}$ \\
Leadership $\rightarrow$ Effectiveness KSFL & $0.273^{* * *}$ \\
Leadership $\rightarrow$ Collaborative culture & $0.85^{* * *}$ \\
& $\mathrm{R} 2$ \\
Effectiveness KSFL & $0.614^{* * *}$ \\
Collaborative culture & $0.722^{* * *}$ \\
\hline${ }^{*} p<0.1,{ }^{* *} p<0.05,{ }^{* * *} p<0.01$ &
\end{tabular}

\section{Hypothesis Testing}

The overall hypothesis testing results are shown in Table 15. Hypothesis $\mathrm{H} 1$ is supported by model 2, model 3 and model 4 but not supported by model 1 due to the mediating effects of the constructs collaborative culture and trust. The support of hypothesis $\mathrm{H} 1$ is in line with the literature that leadership is related to knowledge sharing (Yang, 2007; Islam et al., 2011).

However, $\mathrm{H} 1$ is not supported by model 4 and is not consistent with the literature (Yang, 2007; Islam et al., 2011). It may lie in the reason that the constructs collaborative culture and trust have their mediating effect on the path leadership $\rightarrow$ KSFL. Hypothesis $\mathrm{H} 2$ is supported by model 1 (Figure 2) and model 4 (Figure 5) and our finding is in line with the literature (Islam et al., 2011; Gál, 2012; Schein, 1984; Zehir, Ertosun, Zehir \& Müceldili, 2011). Hypothesis H3 is supported by model 1 and model 5 . Collaborative culture is an open culture to external KSFL. Therefore, the positive relationship between collaborative culture and KSFL is in line with the literature (Cai et al., 2013; Hendriks, 2009; Islam et al., 2011; Liu et al., 2015; Yang, 2007). Hypothesis $\mathrm{H} 4$ is supported by model 1 that there is a direct positive relationship between collaborative culture and trust. $\mathrm{H} 5$ is supported by model 1 and model 3, which is in line with the literature (Islam et al., 2011; Schein, 1984). H6 is supported by model 1 and model 3 that leadership is positively related to trust. However, the support of $\mathrm{H} 6$ by model 1 is not consistent with the finding by Pučètaitè, Novelskaitè \& Markūnaite (2015), who propose that leadership is a mediating variable between organizational culture and trust.

TABLE 15. Hypothesis testing results, H1 H6

\begin{tabular}{lllll}
\hline \hline Hypothesis & Model 1 & Model 2 & Model 3 Model 4 & \\
\hline H1 & not supported & supported & supported & Supported \\
H2 & Supported & Not applicable & Not applicable & Supported \\
H3 & Supported & Not applicable & Not applicable & Supported \\
H4 & Supported & Not applicable & Not applicable & Not applicable \\
H5 & Supported & Supported & Supported & Supported \\
H6 & Supported & Not applicable & Supported & Not applicable \\
\hline \hline
\end{tabular}

ISSN: 2414-309X

DOI: $10.20474 /$ jabs-3.2.4

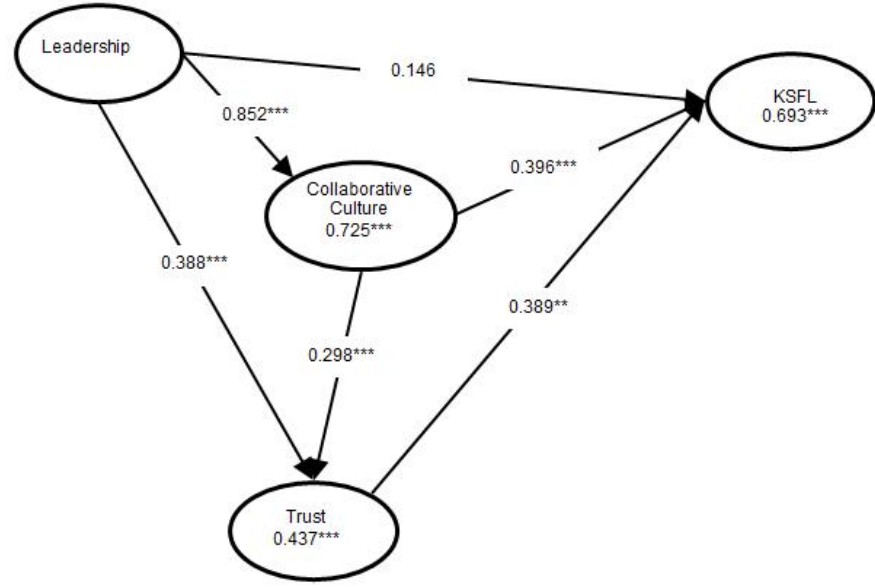

FIGURE 5. Structural model with all mediators' effect (model 1)

The construct collaborative culture mediates the relationship between leadership and KSFL such that the direct effect of leadership $\rightarrow$ KSFL is reduced from 0.735 down to 0.273 . The exogenous variable leadership has an indirect effect of 0.457 on KSFL via the endogenous mediating variable collaborative culture. We conclude that hypothesis $\mathrm{H} 7$ is supported (Table 16).

TABLE 16. Hypothesis testing H7

\begin{tabular}{lllll}
\hline \hline Path & Model 2 & \multicolumn{3}{l}{ Model 4 } \\
\hline & Path Coef. & $\mathrm{R}^{2}$ & Path Coef. & $\mathrm{R}^{2}$ \\
\hline Leadership $\rightarrow$ KSFL & $0.735^{* * *}$ & $0.54^{* * *}$ & $0.273^{* * *}$ & $0.614^{* * *}$ \\
Leadership $\rightarrow$ CC $\rightarrow$ KSFL & & & $0.457^{* * *}$ & \\
Total & $0.735^{* * *}$ & & $0.730^{* * *}$ & \\
\hline${ }^{*} p<0.1,{ }^{* *} p<0.05,{ }^{* * *} p<0.01$ & &
\end{tabular}

H7 is supported. The construct collaborative culture has a strong mediating effect on the relationship between leadership and KSFL. The construct collaborative culture exerts a weak mediating effect on the relationship between leadership and trust, reducing the direct effect leadership $\rightarrow$ trust of 0.646 down to 0.388 , with an indirect effect of 0.254 (Table 17).

TABLE 17. Hypothesis testing H8

\begin{tabular}{lllll}
\hline \hline Path & Model 1 & \multicolumn{3}{l}{ Model 3 } \\
\hline & Path Coef. & $\mathrm{R}^{2}$ & Path Coef. & $\mathrm{R}^{2}$ \\
\hline Leadership $\rightarrow$ trust & $0.388^{* * *}$ & $0.457^{* * *}$ & $0.646^{* * *}$ & $0.418^{* * *}$ \\
Leadership $\rightarrow C \mathrm{CC} \rightarrow$ trust & $0.254^{* * *}$ & & & \\
Total & 0.642 & & $0.646^{* * *}$ & \\
\hline${ }^{*} p<0.1,{ }^{* *} p<0.05,{ }^{* * *} p<0.01$ & &
\end{tabular}

H8 is supported. The construct collaborative culture has a weak mediating effect on the relationship between leader- 
ship and trust. Therefore, hypothesis H8 is supported. The construct trust has a mediating effect on the relationship between leadership and KSFL, reducing the direct effect of leadership $\rightarrow$ KSFL from 0.735 to 0.448 . The indirect effect from leadership through trust to KSFL is 0.286 , which is relatively weak in comparison with the direct effect. However, we conclude that hypothesis H9 is supported (Table 18).

TABLE 18. Hypothesis testing H9

\begin{tabular}{lllll}
\hline \hline Path & Model 2 & \multicolumn{3}{l}{ Model 3 } \\
\hline & Path Coef. & $\mathrm{R}^{2}$ & Path Coef. & $\mathrm{R}^{2}$ \\
\hline Leadership $\rightarrow$ KSFL & $0.735^{* * *}$ & $0.54^{* * *}$ & $0.448^{* * *}$ & $0.654^{* * *}$ \\
Leadership $\rightarrow$ trust $\rightarrow$ KSFL & & & $0.286^{* * *}$ & \\
Total & 0.735 & & $0.734^{* * *}$ & \\
\hline${ }^{*} p<0.1,{ }^{* *} p<0.05,{ }^{* * *} p<0.01$ & &
\end{tabular}

H9 is supported. The construct trust has a weak mediating effect on the relationship between leadership and KSFL. The construct trust exerts a weak mediating effect on the relationship between construct collaborative culture and KSFL, reducing the direct effect of 0.538 down to 0.396 , with an indirect effect of 0.116 . Although the mediating effect is weak, we conclude that hypothesis H10 is supported (Table 19).

TABLE 19. Hypothesis testing H10

\begin{tabular}{lllll}
\hline \hline Path & Model 1 & \multicolumn{3}{l}{ Model 4 } \\
\hline & Path Coef. & $\mathrm{R}^{2}$ & Path Coef. & $\mathrm{R}^{2}$ \\
\hline $\mathrm{CC} \rightarrow$ KSFL & $0.396^{* * *}$ & $0.693^{* * *}$ & $0.538^{* * *}$ & $0.614^{* * *}$ \\
$\mathrm{CC} \rightarrow$ trust $\rightarrow$ KSFL & $0.116^{* * *}$ & & & \\
Total & 0.512 & & $0.538^{* * *}$ & \\
\hline${ }^{*} p<0.1,{ }^{* *} p<0.05,{ }^{* * *} p<0.01$ & &
\end{tabular}

H10 is supported. The construct trust has a weak mediating effect on the relationship between collaborative culture and KSFL. Model 2 shows that leadership has a direct effect of 0.735 on KSFL. The direct effect of leadership on KSFL is reduced by the complex mediating effect of collaborative culture and trust from 0.762 down to a nonsignificant effect of 0.146 at $p<0.1$ level. The total indirect effect of leadership $\rightarrow$ collaborative culture $\rightarrow$ KSFL + leadership $\rightarrow$ collaborative $\rightarrow$ trust $\rightarrow$ KSFL + leadership $\rightarrow$ trust $\rightarrow$ KSFL is 0.587 , which is a strong effect comparing to the insignificant direct effect of 0.146 . We, therefore, conclude that hypothesis $\mathrm{H} 11$ is supported (Table 20). In the next section, we will discuss the significance of our finding in supplier development by knowledge sharing.
TABLE 20 . Hypothesis testing H11

\begin{tabular}{lllll}
\hline \hline Path & Model 1 & \multicolumn{3}{l}{ Model 2 } \\
\hline & Path Coef. & $\mathrm{R}^{2}$ & Path Coef. & $\mathrm{R}^{2}$ \\
\hline Leadership $\rightarrow$ KSFL & $0.146^{*}$ & $0.693^{* * *}$ & $0.735^{* * *}$ & $0.54^{* * *}$ \\
Leadership $\rightarrow \mathrm{CC} \rightarrow \mathrm{KSFL}$ & $0.337^{* * *}$ & & & \\
Leadership $\rightarrow \mathrm{CC} \rightarrow$ trust $\rightarrow$ KSFL & $0.099^{* * *}$ & & & \\
Leaders $\rightarrow$ trust $\rightarrow$ KSFL & $0.151^{* * *}$ & & & \\
Total & 0.733 & & $0.735^{* * *}$ & \\
\hline${ }^{*} p<0.1,{ }^{* *} p<0.05,{ }^{* * *} p<0.01$ & &
\end{tabular}

H11 is supported. The construct collaborative culture and trust have a combined strong mediating effect on the relationship between leadership and KSFL.

\section{DISCUSSION}

Per Schein (1984), organizational culture takes shape after the founder of an organization, implying that there is a hierarchical occurrence of the two constructs. The hierarchical occurrence of leadership, organizational culture, and trust and their relationships with knowledge sharing are translated into several models with respect to the developing stages of an organization. Hair et al. (2017) suggest evaluating the joint mediating effects together instead of individual effect by each mediator to avoid bias. However, per Schein (1984), organizational culture and trust exist after the leadership. We therefore argue that we can obtain more insight by considering the mediating effects individually and jointly.

The individual structural models are model 2, model 3 and model 4. Model 2 illustrates that the supplier firm has only leadership in place, for instance, in the infant stage of the supplying firm (Schein, 1984), knowledge is pursued via knowledge sharing based on the leadership's strategic belief. Model 3 illustrates that the relationship between the supplier firm and the focal firm is resting on both social and organizational trust, with leadership's strategic belief that knowledge has an impact on the firm. Model 4 illustrates that, organizational culture comes into play, mediating the effect of leadership on knowledge sharing. Trust, which is also believed to be a cultural element, is invisible in the culture (Cadden et al., 2013; Iglesias, Sauquet \& Montaña, 2011; Islam et al., 2011; Silahtaroglu \& Vardarlier, 2016).

There are two models in our empirical results. Model 1 is the full model. As shown in model 1, the leadership has a direct as well as an indirect relationship, via the construct collaborative culture and trust, with the KSFL. The organizational behaviour is fully influenced by the founder (Schein, 1984). When the leadership holds the strategic view that KSFL is beneficial, the supplying firm will pursue for effective knowledge sharing (model 2, Figure 3). A sup- 
plier firm may be absent from its organizational culture (model 3), for instance, per Schein (1984), in the early stage of firm development, the collaboration between the supplier and the focal firm relies on social and organizational trust, which is developed by the leaders between the supplier and the focal firm (model 3). Trust is a cultural element of value (Cadden et al., 2013; Iglesias et al., 2011; Islam et al., 2011) and knowledge sharing happens only when trust and commitment exist between the supplier and the focal firm (Albino et al., 1998; Blonska et al., 2013; Cadden et al., 2013; Cai et al., 2013; Fynes, Voss \& De Búrca, 2005; Li et al., 2007; Nagati \& Rebolledo, 2013; Mohanty et al., 2014; Wagner, 2011; Wu \& Lin, 2013; Zhao, Hou, Flynn \& Yeung, 2008).

The supplier leader spends a long time to develop trust with the focal firm (Capaldo \& Giannoccaro, 2015; Fawcett et al., 2012; Islam et al., 2013; Pučètaitè et al., 2015; Volken, 2002). As the supplier firm evolves, the organizational culture develops under the influence of leadership, trust becomes an invisible culture element. Model 4 (Figure 5) suggests the mediating effect of collaborative culture on the relationship between leadership and KSFL. Per model 2 (Figure 3), our finding of a strong relationship of leadership on KSFL is in line with the literature (Yang, 2007; Ayuningrat, Noermijati \& Hadiwidjojo, 2016). However, in the presence of collaborative culture and trust, the influence of leadership directly on KSFL diminishes to an insignificant level, which is not in line with the literature (Model 4). There is a fundamental difference in knowledge sharing in the scenario described by Yang (2007) and others.

Knowledge sharing reported in most of the literature is described as a general and unstructured process (Yang, 2007; Islam et al., 2011) However, the knowledge sharing in our research is a structured, involuntary learning process posting by the focal firm on supplier firms. Kline (2015) defines the involuntary learning process as forced learning. Model 2 suggests that in the presence of collaborative culture, the PSUBs are being influenced by the leadership to learn knowledge from external sources. The presence of collaborative relationship between the focal firm and the supplier firm suggests that the PSUBs also trust that the customer teacher will bring them the needed knowledge to improve their capability. When the collaborative culture of the supply firm grows and roots among the organizational members, the cultural elements will guide the members' behaviour (Kathiravelu, Mansor, Ramayah \& Idris, 2013; Islam et al., 2011; Volken, 2002). The supplier leader tends to continue nurturing the organizational culture of which trust is one of the many cultural elements. This may explain why the relationship between leadership and KSFL is no longer significantly positive. We interpret that this model holds when the organizational culture is nurtured so that the values, beliefs, and norms that the leader holds are already inherited by the leader's followers (Schein, 1984).

\section{MANAGEMENT IMPLICATIONS, CONCLUSION, LIMITA- TIONS, AND FURTHER RESEARCH Management Implication}

Sharing knowledge by teaching is nothing different from formal classroom teaching. It takes many resources to prepare and to implement. However, the effectiveness of knowledge sharing process takes time to justify. Therefore, training and educating the supplier by the customer is resource-intensive supplier development program (Kotabe et al., 2003; Rodriguez et al., 2005). Our study explores a predictable and feasible knowledge sharing process, i.e. forced learning by structured classroom teaching. Under appropriate leadership, collaborative culture, and trust confidently, effective knowledge sharing will be achieved. A focal firm intending to implement KSFL can apply similar survey method to confirm the target supplier has the appropriate leadership, collaborative culture, and trust to ensure successful KSFL and eventually achieve the expected supply chain performance.

\section{Conclusion}

We explored the relationships between leadership, collaborative culture, trust and KSFL, particularly a knowledge sharing process led by a customer, which is scarcely explored in the existing literature. Collaborative culture and trust have significant indirect mediating effects on the direct effect of leadership on KSFL. Knowledge sharing by forced learning suggests involuntary learning until the collaborative culture and trust are cultivated, thereby the employees' learning attitude changes. In the context of the supplier development program by knowledge sharing, which is resource-intensive (Kotabe et al., 2003; Rodriguez et al., 2005), the focal firm has to consider the average level of leadership of the supplier firms, the atmosphere of collaborative culture towards external knowledge and the trust level between the focal firm and the supplier firms.

\section{Limitations}

There are a few limitations of our study. There are only 199 samples. Although the number of samples is larger than the number of samples required by the statistical power esti- 
mated, samples are confounded in eight supplier firms and six of them are mostly in the same industrial sector. The result may have the same predictive power in similar industries, but its application to other industries needs to be studied.

KSFL is a resource-intensive process, even in this research study. Further study of this kind requires a close relationship between the researcher and the participating firms. The knowledge shared by the researcher must be valuable and scarce to the participating firms, otherwise the original trust relationship will be diminished, harmed and even broken.

\section{Further Research}

There are plenty of knowledge sharing practices, for instance, mentoring, supervising, coaching etc. (Dombrowski \& Mielke, 2013; Efron, Winter \& Bressman, 2012; Peeran, 2015; Rudland et al., 2010; Sanfey, Hollands \& Gantt, 2013) and forced learning by classroom teaching (Carr \& Kaynak, 2007) is one of them. The effectiveness of other knowledge sharing mechanism is scarcely explored in the literature. We suggest researchers to explore the relationships between the organizational constructs that may help the industry to justify supplier development investments.

\section{REFERENCES}

Albino, V., Garavelli, A.C., \& Schiuma, G. 1998. Knowledge transfer and inter-firm relationships in industrial districts: The role of the leader firm. Technovation, 19(1): 53-63. DOI: 10.1016/S0166-4972(98)00078-9

Anastas, J.W. 1999. Research design for social work and the human services. New York, N.Y: Columbia University Press. Ayuningrat, M.P., Noermijati., \& Hadiwidjojo, D. 2016. Green product innovation's effect on firm performance of managerial environmental concern and green communication. Journal of Administrative \& Business Studies, 2(2): 56-63.

Asare, A.K., Brashear, T. G., Yang, J., \& Kang, J. 2013. The relationship between supplier development and firm performance: The mediating role of marketing process improvement. Journal of Business \& Industrial Marketing, 28(6): 523-532. DOI: $10.1108 / J B I M-04-2013-0100$

Blonska, A., Storey, C., Rozemeijer, F., Wetzels, M., \& De Ruyter, K. 2013. Decomposing the effect of supplier development on relationship benefits: The role of relational capital. Industrial Marketing Management, 42(8): 1295-1306.

DOI: $10.1016 /$ j.indmarman.2013.06.007

Buckingham, A., \& Saunders, P. 2004. The survey methods workbook: From design to analysis. Malden, MA: Polity Pr.

Cadden, T., Marshall, D., \& Cao, G. 2013. Opposites attract: organisational culture and supply chain performance. Supply Chain Management: An International Journal, 18(1): 86-103. DOI: 10.1108/13598541311293203

Cai, S., Goh, M., De Souza, R., \& Li, G. 2013. Knowledge sharing in collaborative supply chains: Twin effects of trust and power. International Journal of Production Research, 51(7): 2060-2076. DOI: 10.1080/00207543.2012.701780

Cao, Z., Huo, B., Li, Y., \& Zhao, X. 2015. The impact of organizational culture on supply chain integration: A contingency and configuration approach. Supply Chain Management: An International Journal, 20(1): 24-41.

DOI: $10.1108 /$ SCM-11-2013-0426

Capaldo, A., \& Giannoccaro, I. 2015. How does trust affect performance in the supply chain? The moderating role of inter- dependence. International Journal of Production Economics, 166: 36-49. DOI: 10.1016/j.ijpe.2015.04.008

Carr, A.S., \& Kaynak, H. 2007. Communication methods information sharing, supplier development and performance: An empirical study of their relationships. International Journal of Operations \& Production Management, 27(4): 346- 370.

DOI: $10.1108 / 01443570710736958$

Chen, Y.H., Lin, T.P., \& Yen, D.C. 2014. How to facilitate inter organizational knowledge sharing: The impact of trust. Infor- $\quad$ mation \& Management, 51(5): 568-578. DOI: 10.1016/j.im.2014.03.007

Diamantopoulos, A., Sarstedt, M., Fuchs, C., Wilczynski, P., \& Kaiser, S. 2012. Guidelines for choosing between multi-item and single-item scales for construct measurement: A predictive validity perspective. Journal of the Academy of Mar- keting Science, 40(3): 434-449. DOI: 10.1007/s11747-011-0300-3

Dombrowski, U. \& Mielke, T. 2013. Lean leadership fundamental principles and their application. Paper presented at the Forty Sixth CIRP Conference on Manufacturing System, Setubal, PT. DOI: 10.1016/j.procir. 2013.06.034

Edwards, J.R., 2011. The fallacy of formative measurement. Organizational Research Methods, 14(2): 370-388. DOI: $10.1177 / 1094428110378369$ 
Efron, E., Winter, J.S., \& Bressman, S. 2012. Toward a more effective mentoring model: An innovative program of collabora- tion. Journal of Jewish Education, 78(4): 331-361. DOI: 10.1080/15244113.2012.734431

Faul, F., Erdfelder, E., Lang, A.G., \& Buchner, A. 2007. G Power 3: A flexible statistical power analysis program for the social, behavioral and biomedical sciences. Behavior Research Methods, 39(2): 175-191. DOI: 10.3758/BF03193146

Fawcett, S.E., Jones, S.L., \& Fawcett, A.M. 2012. Supply chain trust: The catalyst for collaborative innovation. Business Hori- $\quad$ zons, 55(2): 163-178. DOI: 10.1016/j.bushor.2011.11.004

Fynes, B., Voss, C., \& De Búrca, S. 2005. The impact of supply chain relationship quality on quality performance. Interna- tional Journal of Production Economics, 96(3): 339-354. DOI: 10.1016/j.ijpe.2004.05.008

Gál, M. 2012. Leadership organizational culture: Is there a relationship? Paper presented at The International Confer- ence on Economics and Administration, Faculty of Business and Administration, University of Bucharest, Bucharest, RO.

Garson, G.D., 2013. Research design: Statistical Association blue book series. New Caledonia, NC: Statistical Associates Publishing.

Giannakis, M. 2008. Facilitating learning and knowledge transfer through supplier development. Supply Chain Manage- ment: An International Journal, 13(1): 62-72. D0I: 10.1108/13598540810850328

Hair, J.F., Hult, G.T.M., Ringle, C.M., \& Sarstedt, M. 2014. A primer on partial least squares structural equation modeling (PLS-SEM). Thousand Oaks, CA: Sage Publication.

Halmos, P. R. 1994. What is teaching? The American Mathematical Monthly, 101(9): 848-854. DOI: 10.2307/2975131 Hartnell, C.A., Ou, A.Y. \& Kinicki, A. 2011. Organizational culture and organizational effectiveness: A meta-analytic investigaof the competing values framework's theoretical suppositions. Journal of Applied Psychology, 96(4): 677-694. D0I: $10.1037 / \mathrm{a} 0023086$

He, Q., Gallear, D., \& Ghobadian, A. 2011. Knowledge transfer: The facilitating attributes in supply-chain partnerships. In- formation Systems Management, 28(1): 57-70. DOI: 10.1080/10580530.2011.536114

Hendriks, P. H. 2009. Unveiling the knowledge-sharing culture. International Journal of Learning \& Intellectual Capital, 6(3): 235-256. DOI: 10.1504/IJLIC.2009.025043

Huo, B., Qi, Y., Wang, Z., \& Zhao, X. 2014. The impact of supply chain integration on firm performance: The moderating role of competitive strategy. Supply Chain Management: An International Journal, 19(4), 369-384.

DOI: $10.1108 /$ SCM-03-2013-0096

Iglesias, O., Sauquet, A., \& Montaña, J. 2011. The role of corporate culture in relationship marketing. European Journal of Marketing, 45(4): 631-650. DOI: 10.1108/03090561111111361

Islam, M.Z., Ahmed, S.M., Hasan, I. \& Ahmed, S.U. 2011. Organizational culture and knowledge sharing: Empirical evidence from service organizations. African Journal of Business Management, 5(14): 5900-5909.

Kathiravelu, S.R., Mansor, N.N.A., Ramayah, T., \& Idris, N. 2014. Why organisational culture drives knowledge sharing? Procedia-Social \& Behavioral Sciences, 129: 119-126. D0I: 10.1016/j.sbspro.2014.03.656

Kline, M.A. 2015, How to learn about teaching: An evolutionary framework for the study of teaching behavior in humans and other animals. Behavioral \& Brain Sciences, 38: 1-71.

Kotabe, M., Martin, X., \& Domoto, H. 2003. Gaining from vertical partnerships: Knowledge transfer, relationship duration and supplier performance improvement in the US and Japanese automotive industries. Strategic Management Journal, 24(4): 293-316. DOI: $10.1002 / \mathrm{smj} .297$

Li, W., Humphreys, P.K., Yeung, A.C., \& Cheng, T.E. 2007. The impact of specific supplier development efforts on buyer competitive advantage: an empirical model. International Journal of Production Economics, 106(1): 230-247.

DOI: $10.1016 /$ j.ijpe.2006.06.005

Liker, J. 2004. The Toyota way: 14 management principles from the world's greatest manufacturer. [New York, NY: The McGraw Hill Companies.

Liu, L., Chen, G., \& Niu, X. 2015. Game analysis of the knowledge sharing mechanism for the supply chain collaborative inno- $\quad$ vation. Journal of Industrial Engineering \& Management, 8(1): 152-169. DOI: 10.3926/jiem.1368

Miroshnik, V., \& Basu, D. 2014. Corporate culture in multinational companies: A Japanese perspective. Basingstoke, UK: Palgrave Macmillan. DOI: 10.1057/9781137447661 
Mohanty, M.K., Gahan, P., \& Choudhury, S. 2014. Why most of the supplier development programs fail in discrete manufac- turing findings from selected Indian discrete manufacturing industries. International Journal of Management Science \& Engineering Management, 9(3): 201-211. DOI: 10.1080/17509653.2014.884454

Mortensen, M., \& Arlbjørn, J. 2012. Inter organisational supplier development: The case of customer attractiveness and strategic fit. Supply Chain Management: An International Journal, 17(2): 152-171.

DOI: $10.1080 / 17509653.2014 .884454$

Nagati, H., \& Rebolledo, C. 2013. Improving operational performance through knowledge exchange with customers. Pro- duction Planning \& Control, 24(8-9): 658-670. DOI: 10.1080/09537287.2012.666843

Nicholas, J. 1998. Competitive manufacturing management: Continuous improvement lean production and customer- focused quality. New York, NY: Irwin McGraw-Hill.

Nir, A.S., Ding, J.F., \& Chou, C.C. 2012. Inter organizational culture trust knowledge sharing collaboration and performance in supply chain of maritime industries: Examining the linkages. African Journal of Business Management, 6(19): 5927- 5930.

Peeran, S. 2015. Three tips for effective mentoring: Mentoring young engineering employees is key to their success. Con- sulting Specifying Engineer, 52(3): 11(1).

Pučètaitė, R., Novelskaitė, A. \& Markūnaitė, L. 2015. The mediating role of leadership in building organizational trust on ethical culture of an organization. Economics \& Sociology, 8(3): 11-31. DOI: 10.14254/2071-789X.2015/8-3/1

Ringle, C.M., Wende, S., \& Becker, JM., 2015. Smart PLS 3 boenningstedt smart PLS. URL: goo.gl/g0KbzG. Last accessed on 29 March 2017.

Routroy, S., \& Pradhan, S.K. 2013. Evaluating the critical success factors of supplier development: A case study. BenchmarkAn International Journal, 20(3): 322-341. DOI: 10.1108/14635771311318117

Rudland, J., Bagg, W., Child, S., De Beer, W., Hazell, W. , Poole, P. , \& Wilkinson, T. J. 2010. Maximising learning through effective supervision. The New Zealand Medical Journal, 123: 1309-1311.

Sako, M. 2004. Supplier development at Honda Nissan and Toyota: Comparative case studies of organizational capability enhancement. Industrial \& corporate change, 13(2): 281-308. DOI: 10.1093/icc/dth012

Sánchez-Rodríguez, C., Hemsworth, D., \& Martínez-Lorente, Á.R. 2005. The effect of supplier development initiatives on pur- chasing performance: A structural model. Supply Chain Management: An International Journal, 10(4): $289-301$. DOI: 13598540510612767

Sanfey, H., Hollands, C., \& Gantt, N.L. 2013. Strategies for building an effective mentoring relationship. The American Jour- $\quad$ nal of Surgery, 206(5): 714-718. DOI: 10.1016/j.amjsurg.2013.08.001

Schein, E.H. 1984. Coming to a new awareness of organizational culture. Sloan Management Review, 25(2): 3-16.

Shingo, S. 1988. Non stock production: The Shingo system of continuous improvement. CRC Press. Cambridge, MA: Pro- ductivity Press.

Silahtaroglu, G., \& Vardarlier, P. 2016. Leaders impact on organizational behavior: A text mining study on universities in turkey. International Journal of Business \& Administrative Studies, 2(2): 52-56.

Starnes, B.J., Truhon, S.A. \& McCarthy, V. 2010. A primer on organizational trust organizational trust: Employee employer relationship. URL: goo.gl/7dLt76. Last Accessed on October 152016.

Sundar, C.S., \& Al Harthi, F. N.S. 2015. Impact of capital structure on firm's profitability with reference to companies listed on MSM (Muscat Securities Market). International Journal of Business \& Administrative Studies, 1(1): 23- 28.

Teh, P. L., \& Sun, H. 2012. Knowledge sharing, job attitudes and organisational citizenship behaviour. Industrial Manage- ment \& Data Systems, 112(1): 64-82. DOI: 10.1108/02635571211193644

Volken, T. 2009. Elements of trust: the cultural dimension of Internet diffusion revisited. Information Technology Educa\& Society, 10(2): 45-77. DOI: 10.7459/ites/10.2.04

Wagner, S.M. 2011. Supplier development and the relationship life cycle. International Journal of Production Economics, 129(2): 277-283. DOI: 10.1016/j.ijpe.2010.10.020

Wong, K.K.K. 2013. Partial least squares structural equation modeling (PLS-SEM) techniques using SmartPLS. Marketing Bulletin, 24(1): 1-32. 
Wu, L.W., \& Lin, J.R. 2013. Knowledge sharing and knowledge effectiveness: Learning orientation and co-production in the contingency model of tacit knowledge. Journal of Business \& Industrial Marketing, 28(8): 672-686.

DOI: $10.1108 / J B I M-04-2011-0050$

Yang, J.T. 2007. Knowledge sharing: Investigating appropriate leadership roles and collaborative culture. Tourism Manage28(2): 530-543. DOI: 10.1016/j.tourman.2006.08.006

Zehir, C., Ertosun, Ö.G., Zehir, S., \& Müceldili, B. 2011. The effects of leadership styles and organizational culture over firm performance: Multinational companies in İstanbul. Procedia Social \& Behavioral Sciences, 24: 1460-1474.

DOI: $10.1016 /$ j.jom.2007.08.002

Zhao, X., Huo, B., Flynn, B.B., \& Yeung, J.H.Y. 2008. The impact of power and relationship commitment on the integration between manufacturers and customers in a supply chain. Journal of Operations Management, 26(3): 368-388.

DOI: $10.1016 /$ j.sbspro.2011.09.032

— This article does not have any appendix. - 